\title{
IDIOPATHIC HYPOPARATHYROIDISM
}

BY

F. S. W. BRIMBLECOMBE, M.B., M.R.C.P.

Late Children's Registrar, Harefield E.M.S. Hospital, Harefield, Middlesex

Cases of spontaneous hypoparathyroidism, although rare, have been reported frequently in the literature (as by Albright and Ellsworth (1929), Snapper (1934), Campbell (1935), Himsworth and Maizels (1940), Goerner and Samuelson (1934), and Robertson (1941)). The disease is characterized by increased neuromuscular irritability giving rise to tetany, and by a lowered blood calcium and raised blood phosphorus. Cataracts may develop in untreated cases. Generalized convulsions may occur. Although many cases arise in childhood, the disease may occur at any age, and one patient described by Snapper (1934) did not develop symptoms until the age of 76. The diagnosis is established when other factors causing tetany such as alkalosis, any form of rickets, osteomalacia, coeliac disease, and steatorrhoea have been excluded.

Idiopathic hypoparathyroidism has been described by Hunter (1931) in his classical review of calcium and phosphorus metabolism, as being a condition analogous to myxoedema in relation to hypothyroidism. Symptomatically it is found to be identical with hypoparathyroidism following too extensive thyroidectomy which has included removal of the parathyroid glands.

A case of spontaneous hypoparathyroidism, which has now been under observation for over six years, and which has presented some unusual features is now reported and discussed.

\section{Case Report}

Sylvia A. developed normally until the age of 7 years, having suffered only from acute intussusception as a baby, and measles and whoopingcough in early childhood. At the age of 7, however, it was noticed that her fingers became rigid on first waking up in the mornings, remaining immovable usually for about fifteen minutes. During the spasms her fingers were flexed at the metacarpo-phalangeal joints and extended at the interphalangeal joints. At first these spasms occurred only occasionally but gradually they became more frequent and of longer duration. During them she remained quite conscious and used to laugh at her hands which apparently gave her no pain.

In 1941, at the age of 8 , she developed similar attacks of rigidity of her feet which occurred both at rest and during exercise. During these spasms her feet were held in the position of extreme talipes equino-varus, and she often cried out from the pain in her legs. At this time, also, she began to complain of frontal headaches.

One afternoon in August, 1941, she complained of frontal headache and went to bed. An hour later she was found in bed unconscious with marked pallor and rigidity of all her muscles; there was some froth on her lips and her eyes were open and staring. She recovered in five minutes and fell into a deep sleep. During the next six weeks she had many of these seizures, the number varying between one and five a day. The attacks started without warning, and consisted first of a tonic phase lasting two to five minutes, during which time she was very pale, followed by a clonic period of shorter duration accompanied by opisthotonus, frothing at the mouth, biting of the tongue, and sometimes incontinence of urine; the clonic phase was followed by a period of unconsciousness lasting ten to twenty minutes, after which she would fall into a deep sleep. Between the seizures the spasms of rigidity in her hands and feet continued to occur.

In October, 1941, she was given epanutin gr. $\frac{3}{4}$ at night, and this appeared to reduce the severity of the seizures though it did not abolish them and had no effect on the spasms in her limbs. She was admitted to Harefield Emergency Hospital under the care of Dr. Lightwood on Nov. 13, 1941. Her parents and brother, aged 10, were alive and well, and there was no family history of epilepsy or other disease.

On examination she was found to be afebrile but drowsy. She could, however, be roused to talk intelligently for her age. Examination of her lungs, heart, and abdomen showed no abnormality. Her pupils were equal and active to light, there was no nystagmus, and her eye movements were normal. There was no papilloedema.

No cranial nerve abnormality was detected and her limbs showed no paresis or anaesthesia, all her reflexes were normal. Blood pressure was $105 / 70 \mathrm{~mm}$. Hg. Her weight was $51 \mathrm{lb}$. (normal for age 55 to $60 \mathrm{lb}$.).

Two spasms of her hands occurred on that day, and during each of them her hands were seen to adopt the typical 'main d'accoucheur' position. After the spasms were over Trousseau's and Chvostek's signs were found to be positive. Investigations at this time showed the blood calcium to be $5 \cdot 8 \mathrm{mg}$. 
per $100 \mathrm{ml}$. of blood and $9 \cdot 8 \mathrm{mg}$. blood phosphorus. Carbon dioxide combining power was 50.5 volumes per cent. The urine contained no albumin. Blood urea was $40 \mathrm{mg}$. per $100 \mathrm{ml}$. A chest radiograph was clear, and one of the skeleton showed no decalcification (compared with a control) and no bony abnormalities.

Analysis of the stools gave the following figures: total fat $29 \cdot 6 \mathrm{~g}$. per cent.; neutral fat $1 \cdot 7 \mathrm{~g}$. per cent.; free fatty acid $4 \cdot 1 \mathrm{~g}$. per cent.; fatty acid (as soap) $23 \cdot 8 \mathrm{~g}$. per cent.

The cerebrospinal fluid pressure was $175 \mathrm{~mm}$. of fluid. Queckenstedt's test was normal. There was $20 \mathrm{mg}$. per $100 \mathrm{c} . \mathrm{cm}$. of protein and $720 \mathrm{mg}$. per $100 \mathrm{ml}$. of chlorides. There were 3 lymphocytes per c.mm.

Haemoglobin was 90 per cent. (Haldane), and the blood sedimentation rate $9 \mathrm{~mm}$. in one hour.

In view of these investigations a diagnosis of primary parathyroid tetany was made.

Treatment was started after a week in hospital and consisted first in the administration of calcium lactate, 1 drachm three times a day; but this produced no alteration in her tetany or serum calcium. On Nov. 18, therefore, this treatment was discontinued and vitamin $\mathrm{D}$ therapy was started. An initial daily dose of 18,000 I.U. of vitamin $D_{2}$ (calciferol) was employed for one week but produced no effect on her symptoms or blood chemistry, nor did 36,000 I.U. daily for a similar period. The dose was finally increased to 100,000 I.U. a day, and after two weeks on this treatment both the overt and latent tetany was abolished and her blood calcium rose to $8.9 \mathrm{mg}$. per $100 \mathrm{ml}$., whilst the phosphorus fell to $8.2 \mathrm{mg}$. After a further week her blood calcium had risen to $9 \cdot 8 \mathrm{mg}$. per $100 \mathrm{ml}$.

Daily estimations over the next month showed little alteration in the blood calcium, which remained steady between 9.6 and $10.4 \mathrm{mg}$. per $100 \mathrm{ml}$, while the blood phosphorus fell to $5.0 \mathrm{mg}$. She gained $7 \mathrm{lb}$. in weight during this period and was discharged home on Jan. 18, 1942, free from

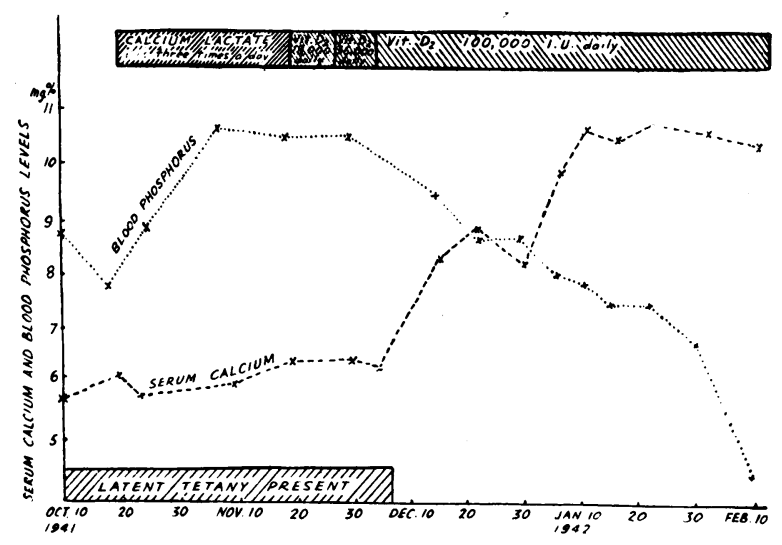

Fig. 1.-Initial response to treatment, 1941-42. symptoms, on a maintenance dose of vitamin $\mathrm{D}$, 100,000 I.U. daily.

During the next two and a half years this dose of vitamin $\mathrm{D}$ was continued, and she was observed at the Hospital for Sick Children, Great Ormond Street, as an out-patient. No untoward symptoms. occurred until June, 1944, when the vitamin D was discontinued. Two weeks after this she developed frank tetany with convulsions which were relieved by the injection of intravenous calcium gluconate. Blood calcium at this time was $8.2 \mathrm{mg}$. per $100 \mathrm{ml}$. The vitamin $\mathrm{D}$ was immediately restarted, no further tetany occurred, and her blood calcium returned to normal.

In August, 1944, she developed vomiting, generalized abdominal pain, and constipation, and was admitted to another hospital. She was discharged home after a week, no diagnosis having been made.

After this she continued to have attacks of vomiting, particularly in the mornings, associated with increasing anorexia. She complained of right frontal headaches and became increasingly listless and unco-operative. She was readmitted to Harefield Emergency Hospital in November, 1944, having lost $17 \mathrm{lb}$. in weight in the previous five months.

Examination now revealed that she was a tall, thin, lethargic girl with sunken eyes and somewhat hirsute skin; she had slight bilateral conjunctivitis. Her lungs were clear. Her pulse was regular at 80 to the minute, and the blood pressure was $115 / 70 \mathrm{~mm}$. Hg. There was no cardiac enlargement and no murmurs. Her abdomen showed no abnormality. Her central nervous system was normal, and Trousseau's and Chvostek's signs were negative. A chest radiograph was clear. No calcification was seen in a radiograph of the abdomen, and renal outlines appeared normal. A radiograph of the skeleton showed normal calcification (as compared with a control). No bony abnormality was seen.

Serum calcium (thrice repeated) was $15.6 \mathrm{mg}$. per $100 \mathrm{ml}$., blood phosphorus $5.4 \mathrm{mg}$., blood phosphatase 20 (King) units, serum sodium $316 \mathrm{mg}$., serum potassium $18 \mathrm{mg}$., and blood chlorides $590 \mathrm{mg}$.

There was a trace of albumin in the urine, no sugar, and a few granular casts and pus cells. The Addis count was 9 million red cells per twelvehour specimen. Blood urea was $81 \mathrm{mg}$. per $100 \mathrm{c.cm}$. The urea clearance test (thrice repeated) showed 22 per cent. normal function. The specific gravity test showed dilution to specific gravity of 1002, no concentration above 1010 . The blood sedimentation rate was $35 \mathrm{~mm}$. in one hour.

Whilst these investigations were being carried out, her maintenance dose of vitamin D was continued, and her marked listlessness, anorexia, frontal headaches, and an irritating continuous dry cough persisted. Over the period from Dec. 28 until Jan. 9, however, her dose of vitamin D was gradually 


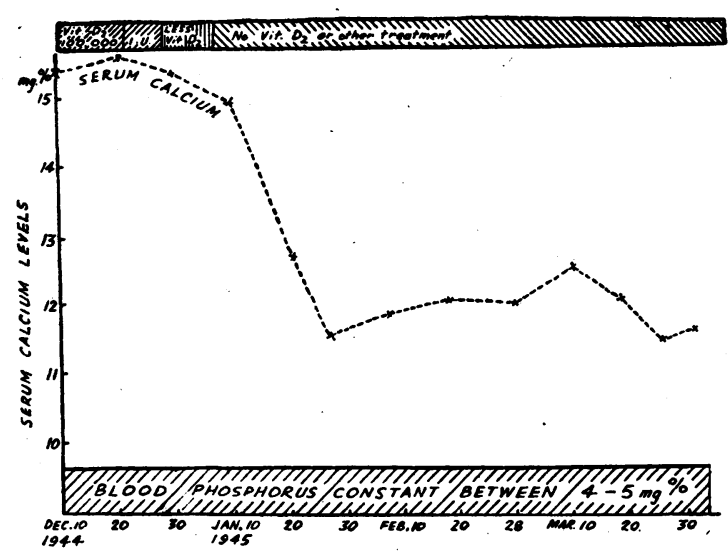

FIG. 2.-Response to withdrawal of treatment, 1944-45.

reduced from 100,000 I.U. to nothing, but on Jan. 12 her blood calcium was still $14.6 \mathrm{mg}$. per $100 \mathrm{ml}$. and her blood phosphorus $4.6 \mathrm{mg}$. During the next three weeks, however, her blood calcium fell steadily till on Jan. 26 it was only $11.4 \mathrm{mg}$. per $100 \mathrm{ml}$. and her blood phosphorus $4.8 \mathrm{mg}$. During this period, also, all her symptoms disappeared and she gained $7 \mathrm{lb}$. in weight.

She remained in hospital until May, 1945, during which time she was given no vitamin $D$ and her blood calcium remained steady between 11.0 and $12.0 \mathrm{mg}$. per $100 \mathrm{ml}$. and her blood phosphorus between $4 \cdot 2$ and $4.8 \mathrm{mg}$. She gained a further $8 \mathrm{lb}$. in weight during this time, remaining free from symptoms throughout, except that she had some recurrent staphylococcal furunculosis in both ears which disappeared after treatment with staphylococcus toxoid, and a transient right-sided facial palsy (lower motor-neurone in type) which cleared after eight weeks.

Prior to discharge her urine contained no albumin or casts, and her blood urea was $65 \mathrm{mg}$. per $100 \mathrm{ml}$. A urea clearance test still showed her renal function to be only 23 per cent. of normal.

She continued as an out-patient at the Hospital for Sick Children, Great Ormond Street. Satisfactory progress was maintained, and in July, 1945, her blood calcium was still $10.4 \mathrm{mg}$. per $100 \mathrm{ml}$.

At the end of August, 1945, however, she developed anorexia, listlessness and vertigo, and on Sept. 11 examination showed serum calcium to be $6.2 \mathrm{mg}$. per $100 \mathrm{ml}$., and blood phosphorus $6.3 \mathrm{mg}$.; latent tetany was present. She was admitted to the Hospital for Sick Children, Great Ormond Street, London.

Renal investigation now showed the urine to have a specific gravity of 1021. There was a trace of albumin but no casts. The Addis count was 6 million red cells in a twenty-four hour specimen. The blood urea was $37 \mathrm{mg}$. per $100 \mathrm{ml}$. and urea clearance 50.5 per cent. of normal function. An intravenous pyelogram was within normal limits but concentration was poor in the left kidney.
An electro-encephalogram carried out at this time showed irregular delta-wave activity (abnormal for age) which suggested acquired dysfunction.

Treatment with calciferol, 100,000 units daily, was restarted, and by Oct. 2 her latent tetany had disappeared and she was free from symptoms and gaining weight. She was discharged on a maintenance dose of calciferol, 50,000 units daily.

In November, 1945, her family removed to Birmingham and observation was continued at the Birmingham Children's Hospital under the care of Dr. A. V. Neale. Her maintenance dose of vitamin $D$ was continued and she exhibited no further untoward effects. In January, 1948, she was working as a factory hand and leading a normal life. One further investigation was carried out. In January, 1946, her vitamin D was temporarily withdrawn and in two months she had reverted to a state of hypocalcaemia and latent tetany.

\section{Discussion}

There has been considerable discussion in the past concerning the long-term therapy of hypoparathyroidism. Although Campbell (1935) has reported a favourable response in some cases to a high-calcium-low-phosphorus diet together with oral hydrochloric acid, the majority of cases have been treated with vitamin $D$.

In America, Albright $(1939,1941)$ has shown good results with A.T.10 (7 dehydro-cholesterol), but in this country Himsworth and Maizels (1940) state that in this condition A.T.10 has little or no advantage over vitamin $D_{2}$ (calciferol).

The dangers of vitamin $D$ overdosage have long been recognized and were extensively reviewed by Harris (1932). Hypervitaminosis usually develops after long continued vitamin D therapy due to a cumulative action. This property of cumulative action has been used in this country by Krestin (1945) when giving a single massive dose of vitamin $D$ in the preventive treatment of rickets.

It is, therefore, surprising that after having taken her stabilizing dose of calciferol, 100,000 units daily, from January, 1942, until June, 1944, our patient should revert to hypocalcaemia with frank tetany only two weeks after her vitamin $D$ had been discontinued. It can only be assumed that this dose was the bare maintenance one for her requirements.

But only two months after the same dose of vitamin $\mathrm{D}$ had been recommenced she began to develop the classical symptoms of hypervitaminosis $\mathrm{D}$, with lassitude, depression, severe anorexia, constipation, and wasting, with hypercalcaemia and renal damage as described by Harris (1932). There was, however, no radiological evidence of metastatic calcification or increased bony calcification.

Four months elapsed, after the onset of hypercalcaemic symptoms, before she was admitted to our hospital and the vitamin D was discontinued. In less than four weeks after this the blood calcium 
had returned to normal and all her symptoms had disappeared. Evidence of renal damage, however, persisted.

Her blood calcium then remained normal with no treatment for eight months. This is in marked contrast to the events following the previous cessation of treatment in June, 1944, when tetany had developed only two weeks after the stoppage of vitamin D therapy.

Parathyroid hypertrophy following renal damage was recognized by MacCallum (1905), and has since been recorded on numerous occasions. The possibility was, therefore, considered that the long period of normal blood calcium in our patient was the result of parathyroid hypertrophy produced by her renal damage. Recent work by Gilmour (1947) has shown that the stimulus for parathyroid hypertrophy in renal damage is most probably hypocalcaemia, itself a secondary consequence of the phosphorus retention and hyperphosphataemia.

Our patient, however, at the time of her renal damage had marked hypercalcaemia, so that it is most unlikely that the renal damage can have stimulated her parathyroid secretion.

The blood calcium and phosphorus levels during the period of renal damage are more probably due to accumulation of vitamin $D$ in considerable quantity during the period of overdosage. When at the end of eight months the supply of vitamin D was exhausted, the patient reverted to her previous state of hypocalcaemia, hyperphosphataemia, and latent tetany. The effects of hypervitaminosis $D$ on her kidneys had also lessened, and her renal function had improved considerably.

When she reverted to a latent tetanic state again at the end of the eight-month period, it was found that her daily requirements of vitamin $D$ had dropped from the previous level of 100,000 I.U. daily to 50,000 I.U. daily, and this dose has been maintained subsequently. One further experiment was tried in January, 1946, when her vitamin D was discontinued; in two months she reverted to hypocalcaemia and latent tetany.

It was apparent, therefore, that in August, 1944, her requirements of vitamin D had lessened for a reason which is not understood but which may have been related to the onset of puberty, and that continuation with her original dosage gave rise to symptoms of hypervitaminosis. When these had subsided it was found that her requirements of vitamin $\mathbf{D}$ had decreased to half the original dosage.
It is greatly to be regretted that circumstances prevented us from carrying out calcium and phosphorus balance estimations which might have been of value in the investigation of this case.

\section{Summary}

A case of idiopathic hypoparathyroidism is described which responded adequately for two and a half years to a maintenance dose of vitamin $D_{2}$, 100,000 units daily. At the end of this time tetany developed after the vitamin $D$ had been discontinued for only two weeks. Two months after the resumption of vitamin $\mathbf{D}$ therapy, symptoms of hypervitaminosis $\mathbf{D}$ developed with renal damage. After a period of eight months with no vitamin $D$, during which all symptoms had disappeared and the renal damage had improved, symptoms of tetany reappeared.

The patient has now been restabilized on a dose of vitamin $D_{2}, 50,000$ units daily, for over two years. She is well and working. Some possible explanations for this chain of events are suggested.

My thanks are due to Dr. Reginald Lightwood and Dr. A. V. Neale for permission to publish this case, to Dr. Reginald Lightwood for help and encouragement in the preparation of the report, and to Dr. Addenbrooke for the clinical details since November, 1945.

\section{REFERENCES}

Albright, F., and Ellsworth, R. (1929). J. clin. Invest., $7,183$.

(1941). J. Amer. Med. Ass., 117, 527. (1939). Ibid., 112, 2592.

Campbell, D. (1935). Lancet, 1, 369.

Gilmour, J. R. (1947). The Parathyroid Glands and Skeleton in Renal Disease. Oxford Medical Publications. London.

Goerner, A., and Samuelsen, G. (1934). J. Amer. med. Ass., 102, 1001.

Harbitz, F. (1915). J. Med. Res., 32, 361.

Harris, L. J. (1932). Lancet, 1, 1031.

Himsworth, H. P., and Maizels, M. (1940). Ibid. 1, 959.

Hunter, D. (1931). Quart. J. Med., 24, 393. (1937). Brit. med. J., 1, 929. (1937). Ibid., 1, 982 .

Krestin, D. (1945). Lancet, 1, 781.

MacCullum, W. G. (1905). Johns Hopk. Hosp. Bull., $16,87$.

Robertson, J. D. (1941). Sancet, $2,156$.

Snapper, I. (1934). Ibid., 1, 728. 